\title{
Searching for the Achilles heel of FOXP3
}

\author{
Teresa Lozano, Noelia Casares and Juan José Lasarte* \\ Gene Therapy and Hepatology Area, Center for Applied Medical Research (CIMA), University of Navarra, Pamplona, Spain
}

\section{Edited by:}

Hans-Uwe Simon, University of Bern Switzerland

Reviewed by:

Stephan von Gunten, University of Bern, Switzerland

Robert Friis, University of Bern,

Switzerland

\section{*Correspondence:}

Juan José Lasarte, Gene Therapy and Hepatology Area, Center for Applied Medical Research (CIMA), University of Navarra, Avenida Pío XII, 55, Pamplona 31008, Spain

e-mail: jjlasarte@unav.es
FOXP3 is a multifaceted transcription factor with a major role in the control of immune homeostasis mediated by $T$ regulatory cells (Treg). The immunoregulatory function of FOXP3 may hinder the induction of immune responses against cancer and infectious agents, and thus, development of inhibitors of its functions might give new therapeutic opportunities for these diseases. But also, FOXP3 is an important tumor suppressor factor in some types of cancers, and therefore, understanding the structure and function of FOXP3 is crucial to gaining insights into the development of FOXP3-targeted therapeutic strategies. FOXP3 homodimerize and likely form supramolecular complexes which might include hundreds of proteins which constitute the FOXP3 interactome. Many of the functions of FOXP3 are clearly regulated by the interactions with these cofactors contributing importantly on the establishment of Treg-cell signature. We summarize here the structural/functional information on this FOXP3 complex, to identify potential opportunities for the development of new strategies to modulate FOXP3 activity.

Keywords: foxp3, FOXP3 interactome, Treg, drug discovery, immunosuppression

\section{FOXP3, A MEMBER OF FOX FAMILY, WITH}

\section{IMMUNOREGULATORY PROPERTIES}

Forkhead (FKH) proteins are a very large family of transcription factors implicated in a variety of cellular processes (1). They are characterized by the presence of a highly conserved 100 amino-acid FKH-binding domain (FKH). The crystal structure of the FKH domain bound to DNA has been solved and has been described as a "winged-helix" similar to the shape of a butterfly (2).

In the last years, more than 100 members, classified in 15 subfamilies of FOX proteins, have been identified (3). They are commonly associated with the regulation of development. Whereas the FKH domain defines this class of transcription factors, other portions of the Fox proteins, which encode for instance transactivation or trans-repression domains, are highly divergent and little is known about their interactions with the transcriptional machinery.

FOX gene mutations have been found to be responsible for diverse phenotypes, from craniopharyngeal development (FOXE1), hair development (Foxq1 and Foxn1) to speech and language development (FOXP2) and hearing (Foxi1) (4). In the last years, it has become clear that these winged-helix proteins have crucial roles in various aspects of immune regulation. Thus, the scurfy mutant mouse strain, which suffers from a fatal lymphoproliferative disease leading to early death within 3-4 weeks of age, presents a frame-shift mutation of the FKH box transcription factor Foxp3 responsible of this disease (5). This affection is characterized by splenomegaly, insulitis, hepatomegaly, lymphadenopathy, and massive lymphocytic infiltrates in the skin and liver, suggesting that mutation in FOXP3 leads to an autoimmune disease.

In humans, mutations in FOXP3 results in an autoimmune syndrome termed IPEX (immunodysregulation, polyendocrinopathy enteropathy, X-linked syndrome), an X-linked immunodeficiency syndrome characterized by insulin-dependent diabetes, thyroiditis, massive T-cell infiltration in multiple organs and chronic wasting (6-8).

Analysis of FOXP3 expression revealed that it was most highly expressed in lymphoid organs, such as the thymus and spleen, and more specifically by CD4+ T cells. The relevance of Foxp3 expression in $\mathrm{CD} 4+\mathrm{T}$ cells was evidenced when it was found that adoptive transfer of wild-type CD4+CD8- lymphocytes could control the $\mathrm{T}$ cells of scurfy mice, thereby preventing the development of disease (9). This observation suggested that CD4+ T cells expressing the wild-type Foxp3 gene played a regulatory role being able to suppress the activity of other immune cells. This was confirmed when CD4+CD25+ T cells were identified as cells able of suppressing proliferation and cytokine production of TCRstimulated conventional CD4+ T cells $(10,11)$. Foxp3 expression in $\mathrm{CD} 4+\mathrm{T}$ cells was found to be sufficient to mark these cells as regulatory (Treg cells). Indeed, infection of CD4+CD25- T cells with a retrovirus expressing Foxp3, converted them to a regulatory phenotype, able to suppress proliferation of conventional CD4+ CD25- T cells (12) and protect mice from autoimmune gastritis. These studies demonstrated that $\mathrm{CD} 4+\mathrm{CD} 25+\mathrm{T}$ regulatory cells with a major role in the suppression of autoreactive $\mathrm{T}$ cells, and preventing autoimmunity. The activity of Foxp3 was also confirmed in transgenic mice overexpressing Foxp3 (13), and curiously, it was found that also CD8+ T cells overexpressing Foxp3 displayed in vitro regulatory activity, showing that Foxp3 expression on non-CD4 T cells was also capable to re-program the cell phenotype.

\section{FOXP3 AND CANCER}

Treg cells inhibit activation of other $\mathrm{T}$ cells and are needed for protection against autoimmune diseases. However, immunoregulatory function of Treg may hinder the induction of immune responses against cancer and infectious agents (14-20). Indeed, Treg capable of suppressing the in vitro function of tumor-reactive 
T cells have been found in humans in many types of tumors (16-18, 20) and have been associated with a high death hazard and reduced survival (16-18). However, there are discrepancies in the prognostic studies relying on the presence of Treg in tumor infiltrates, and paradoxically, a high density of FOXP3 + T-cell infiltration was associated with improved overall survival in patients with colorectal, head and neck carcinoma, or patients with lymphoma (21-23). It has been postulated that Treg could in these cases modulate the tumor microenvironment and influence the biologic behavior of tumoral cells. A better understanding of the biologic role of FOXP3-positive Tregs in these tumors is needed.

Despite a clear role in Tregs, FOXP3 protein expression is not restricted to the lymphocyte lineage but is also present in normal and cancer cells of non-hematopoietic origin (24-28). The function of FOXP3 in cancer is somehow contradictory. Regarding the expression of FOXP3 in human cancer cells and in their normal homologs, two opposite situations have been found. It has been described that in pancreatic cancers or in melanoma, FOXP3 expression is restricted to the tumor cells $(24,25)$. In contrast, FOXP3 appears to be expressed in normal epithelial cells of human breast and prostate, but downregulated in the corresponding cancer cells $(29,30)$. These data suggest a dual role of FOXP3, one linked to immune escape and another to tumor suppression (31).

On the one hand, it has been shown that FOXP3 expression in melanoma cells (26) or in pancreatic carcinoma cells (25) renders the tumor cells suppressive with Treg-like activity to directly inhibit the proliferation of T cells and suggesting a possible mechanism of tumor resistance to immune system. However, on the other hand, several works have demonstrated that the expression of FOXP3, especially in breast cancer cells, is an X-linked cancer suppressor gene and an important regulator of the epidermal growth factor receptor (HER2/ErbB2) and SKP2 oncogenes (27, 30). The expression of Foxp3 has been evidenced in a significant number of cancer types, although its role in tumor progression remains to be elucidated (32).

\section{THE INTERACTOME OF FOXP3}

FOXP3 is essential for the specification and maintenance of Treg cells, and thus, it was considered as the "master regulator" of Treg cells although it was described that cells with many of the Treg-cell characteristics, can differentiate at least transiently, in the absence of FOXP3 $(33,34)$. The molecular basis of FOXP3 function has been poorly understood. As described above, genome-wide analyses of Foxp3 targets has revealed that FOXP3 induces both activation and repression of its target genes (33-37). The capacity of FOXP3 to bind DNA is critical for its functionality; however, it is clear that FOXP3-DNA interactions are assisted by FOXP3 cofactors and by multimerization. After a careful meta-analysis that combined gene-expression profiles, generated in several parallel experiments, Hill et al. identified 603 target genes (407 overexpressed and 196 underexpressed) that compose the canonical Treg-cell signature (38). Importantly, it was found that much of the Treg-cell signature was not ascribable to Foxp3 because it contained gene clusters that are co-regulated with, but not transactivated by FOXP3. Recently, Samstein et al. (39) examined chromatin accessibility of FOXP3-bound enhancers in Treg cells and Foxp $3^{-} \mathrm{CD}^{+} \mathrm{T}$ cells. They showed that FOXP3 was bound mainly to enhancers already accessible in precursor $\mathrm{CD}^{+}{ }^{+} \mathrm{FOXP}^{-} \mathrm{T}$ cells, with only a small subset of exclusively Treg-restricted enhancers found in several genes important for Treg-cell function. Analysis of DNA sequences at FOXP3-binding sites identified a FKH motif only in a small subset of these DNA regions (39), suggesting the contribution of other cofactors on the establishment of Treg-cell signature.

Indeed, it has been described that FOXP3 homodimerize and likely form supramolecular complexes (40). Growing numbers of transcription factors that interact with FOXP3 are being identified and some have been implicated in the Treg-cell-specific geneexpression program $(37,40,41)$. In a recent paper, a chromatographic analyses of nuclear lysates revealed that FOXP3 protein was present in large $400-2,000 \mathrm{kDa}$ complexes (41). In this work, Rudra et al. identified 361 partners of FOXP3 by using a proteomic approach. They found that these partners were implicated in several biological processes such as DNA binding, transcription regulator activity, chromatin binding, regulation of transcription, chromosome organization, chromatin modification as well as RNA binding, processing, splicing, and metabolism suggesting a yet unexplored RNA-associated role of FOXP3. Recently, Fu et al. by using computational network inference, confirmed that FOXP3 expression was responsible of around $10 \%$ of the whole Treg signature and identified five transcription factors (Eos, IRF4, Satb1, Lef1, and GATA-1), which they named "the quintet" that interact with and act together with FOXP3 to elicit much of the characteristic Treg-cell transcriptional signature (37).

This observation is consistent with the fact that the majority of FOXP3-binding sites in the genome lack an identifiable FKHbinding motif in Treg cells and suggests that FOXP3 cofactors may facilitate binding of FOXP3 to a given site either through direct recruitment of FOXP3-containing complexes or through facilitating interactions with FOXP3-bound sites containing FKH motif via loop formation $(35,36,39)$. It is clear that FOXP3 functions, and consequently the phenotype of the FOXP3-expressing cell may change depending on the partners forming the FOXP3 interactome, which might in addition, depend on the activation status of the cell.

A significant number of FOXP3-interacting proteins have been identified, including TIP60, HDAC7, HDAC9, Eos, Irf4, and Hif- $1 \alpha$ $(40,42-48)$. The proteomic analysis of FOXP3-complexes conducted by Rudra et al., found that the majority of FOXP3 partners consisted of proteins that have been implicated in regulation of transcription including many sequence-specific transcription factors such as NFATc2, Runx1, Bcl11b, Foxp1, Foxp4, GATA-3, STAT3, Ikaros (Ikzf1), Aiolos (Ikzf3), Ets, and Cnot3. It has been postulated that the differentiated state of Treg cells is not determined by individual regulatory components, but instead by the collective activity of their transcriptional network $(37,41,49)$. This hypothesis has important implications on the functionality of Tregs, and raises new possibilities for the design of new therapies where Treg cells or FOXP3 expression and function have pathological consequences. Indeed, those strategies able to inhibit a particular interaction with FOXP3, or able to modify the FOXP3 interactome might have important consequences on the whole transcriptome signature of the FOXP3-expressing cell and consequently, on its activity. Thus, a structure/function analysis of 
FOXP3 might help on the understanding of the rules governing the formation of such interactome.

\section{THE STRUCTURE/FUNCTION ANALYSIS OF FOXP3}

The FOXP3 gene is located on the $\mathrm{X}$ chromosome and contains 11 coding exons (exons 1-11) and 3 non-coding exons (5). FOXP3 has various distinguishable functional domains: (i) an N-terminal domain (from a.a. 1 to 193, with two proline-rich regions) responsible for transcriptional repression, (ii) a zinc finger (a.a. 200-223) and a leucine-zipper (LZ)-like motif (a.a. 240-261) (ZL domain) located in the center of the protein, which facilitates the formation of FOXP3 homo-dimers or tetramers, and (iii) the highly conserved carboxy terminal FKH domain (FKH; from a.a. 338 to 421) responsible for the DNA binding. The analysis of FOXP3 variants containing mutations found in IPEX patients have offered some evidences about the function of these domains. Mutations have been found throughout FOXP3 indicating that these regions of the protein are important for proper function $(50,51)$. Identification of the functional consequences of these individual mutations is critical to gain insights into possible treatments for Foxp3-related pathologies.

\section{THE AMINO TERMINAL REGION OF FOXP3}

The N-terminal of FOXP3 has been involved in the interaction with several transcription factors, which are related to the suppressive transcriptional activity of FOXP3. Lopes et al. evaluated the location of point mutations identified in a large cohort of patients with the IPEX syndrome, and found them to cluster primarily in the FKH domain and the leucine zipper, but also in the N-terminal portion of the protein (51). They identified a functional domain in this N-terminal region of FOXP3 which is required for FOXP3mediated repression of transcription. They mapped the functional repressor domain between aminoacids 67 and 132 .

One of the key features of Treg cells is to maintain the anergic status in response to stimulation. In this regard, Lee et al. found that the N-terminus of FOXP3 specifically interacts with and alters subnuclear localization of phosphorylated c-Jun (52), a member of the AP-1 transcription factors which participates in the control of cell proliferation, differentiation, cell death, and cell transformation in response to stimuli (53). This interaction inhibits the promoter DNA-binding activity of c-Jun and induces T-cell anergy.

As mentioned above, FOXP3 expression is not restricted to the lymphocyte lineage but it is also present in cancer cells, especially in breast cancer cells, where it has been demonstrated to be a cancer suppressor gene and an important regulator of the HER2/ErbB2 and SKP2 oncogenes $(27,30)$. It has been described that this tumor suppressor activity is located in the N-terminal region of Foxp3, since a C-truncated versions of the protein do not retain this property (54). The authors described that this activity was independent of NFAT-FOXP3 interaction which is located in the FKH region of FOXP3 (55). It is tempting to postulate that the tumor suppressor activity of Foxp3 is mediated by its capacity to alter the activation of AP-1 through its interaction with c-Jun.

The suppression of CD4+ T cells proliferation is also maintained through the interaction of Foxp3 N-terminal domain with Eos, a zinc-finger transcription factor of the Ikaros family (45).
Foxp3, Eos, and the C-terminal binding protein-1 (CtBP1), form an inhibitory complex that suppresses the expression of genes. Disruption of the interaction of Foxp3 and Eos leads to the failure of Treg to inhibit proliferation of T effector cells. The proline rich $\mathrm{N}$-terminal region of FOXP3 seems to be the responsible for this interaction. However, this region alone is not sufficient to confer Treg cells suppressive function, and NFAT-FOXP3 interaction through the FKH domain is also required $(46,52,55)$. In a recent paper, a new human-specific FOXP3-interacting protein which couples FOXP3 to a chromatin-remodeling complex has been identified to contact with this region (aa 106-198) (56). The authors show that FIK protein (FOXP3-interacting KRAB domain containing protein), acts as a bridging molecule to link FOXP3 with the chromatin-remodeling scaffold protein KAP1 (TIF-1 $\beta /$ TRIM28) and that disruption of this complex restores the expression of genes inhibited by FOXP3, and the suppressor activity of Tregs. Interestingly, expression of genes that were shown to be positively regulated by FOXP3 (such as CTLA4 or CD25) was not affected, suggesting that they were regulated by a different mechanism.

In humans, there are two FOXP3 isoforms expressed in Treg cells that lacks exon 2 (57), located in the N-terminal region of FOXP3. It has been described that exon 2 is implicated in the interaction with $\operatorname{ROR} \alpha$ and $\operatorname{ROR} \gamma \mathrm{t}$, transcriptional factors that activate the expression of IL-17 and IL-22, which are related with Th17 differentiation. ROR $\gamma$ t binds to IL-17A promoter and the interaction of Foxp3 with ROR $\gamma$ t through exon 2 region of Foxp3 is able to suppress of ROR $\gamma \mathrm{t}$-mediated IL-17A promoter activation. These results highlight the importance of Foxp3 N-terminal domain in balancing the differentiation between Treg cells and Th17 $(58,59)$.

The N-terminal of FOXP3 is also reported to interact with c-Rel $(60,61)$, a member of the NF- $\kappa$ B family that is responsible for the up-regulation of a variety of pro-inflammatory cytokines such as IL-6, IL-12, IL-15, IFN- $\gamma$, or IL-2 $(62,63)$. Deletion of exon 1 was sufficient to almost entirely abrogate c-Rel binding, although other regions of FOXP3, such as exon 6 or exon 8 also abolished binding, suggesting that dimerization of Foxp3 or the interaction with other proteins is required. The interaction between Foxp3 and cRel may also contribute to the nuclear translocation of FOXP3. Indeed, it has been shown that FKH-deleted FOXP3, which is mainly located at cytoplasm, was predominantly found in the nucleus in the presence of ectopically expressed c-Rel $(60,61)$.

In addition to the interaction with a number of transcriptional factors, FOXP3 also interacts with enzymes that regulate the activity of FOXP3 at post-translational level [reviewed in (64)]. Among these enzymes, histone acetyltransferase (HAT) TIP60 and histone deacetylase HDAC7 interact with the N-terminal of FOXP3 and increase its suppressive transcriptional activity (43). TIP60 promotes the acetylation of FOXP3, which enhances the suppressive transcriptional activity of FOXP3, but TIP60 may also play a role in regulating FOXP3 activity independent of its HAT activity. The N-terminal 106-190 aa of FOXP3 are required for TIP60-FOXP3, HDAC7-FOXP3 association, as well as for the transcriptional repression of FOXP3 via its FKH domain (43). Binding of TIP60 with FOXP3 may regulate the oligomerization status of FOXP3 and therefore its DNA binding. Moreover, TIP60 
may also recruit additional factors required for transcriptional repression/activation. A clear understanding of the involvement of HDACs in the FOXP3 complex assembly will lead to insights to develop new strategies to modulate Treg functions for human disease (64).

Several of these interactions have been linked to a particular Treg-cell transcriptional profile. This is the case for IRF4 or STAT3, which can affect, alone or in combination with FOXP3, some segments of the Treg-cell signature $(47,65)$. Their presence should modulate the range of Treg effector functions. In this way, it has been reported that a modification of the $\mathrm{N}$ terminus of Foxp3, results in diametrically opposite effects in the severity of different autoimmune diseases. Mice expressing the GFP-Foxp 3 fusion protein modified Foxp 3 molecular interactions, blocking HIF-1 $\alpha$ but increasing IRF4 interactions and resulted in a divergent susceptibility to autoimmune disease: protection against antibody-mediated arthritis, but greater susceptibility to diabetes (66). Thus, specific subfunctions of Treg cells and the immune diseases they regulate can be influenced by Foxp3's molecular interactions with particular partners, which result in different patterns of immunoregulation.

\section{ZINC FINGER AND LEUCINE ZIPPER}

Dimerization of FOXP3 is required for its function as a transcriptional regulator and the LZ of FOXP3 is necessary and sufficient for this association $(40,51,64,67)$. In addition, the LZ of FOXP3 is implicated in the hetero-association with FOXP1 $(64,68)$. The disease-associated mutations of the LZ domain disrupting FOXP3 dimerization can substantially reduce the binding of FOXP3 to promoter regions in vivo $(40,51,64,67)$. These findings indicate that the FOXP3 protein ensemble, as well as its DNA-binding properties, could be modulated through oligomerization of the LZ region. Song et al. have characterized the structure of the FOXP3Zinc finger and LZ (FOXP3-ZL) domain and identified two lysine residues in the $\mathrm{LZ}$ region (K250 and K252) as key residues for the conformational change and stability of the FOXP3 dimer. Acetylation of these $\mathrm{K}$ residues would neutralize the positive charges at these sites through which the FOXP3 dimer stability is modulated and result in changes in promoter occupancy, histone acetylation patterns, IL-2 gene-expression levels, and Treg suppression activity.

Moreover, the $\mathrm{LZ}$ is also important for the interaction between histone H1.5 and FOXP3, which cooperatively repress IL-2 transcription in human $\mathrm{T}$ cells. This interaction alters histone H1.5 binding to target genes (i.e., IL-2 or CTLA4) to modulate their expression and to program Treg function (69). Also, FOXP1FOXP3 hetero-associations through the LZ domain may compete with FOXP3 homo-dimerization and the dynamic balance of discrete forms of FOXP3-complexes may directly affect its repressor activity (69).

FOXP3 interacts physically with the transcription factor AML1 (acute myeloid leukemia 1)/Runxl (Runt-related transcription factor 1) (44), which is crucially required for normal hematopoiesis including thymic T-cell development. Ono et al. showed that this interaction suppresses IL- 2 and IFN- $\gamma$ production, upregulates Treg-associated molecules, controls anergy of the cell and exerts suppressive activity. They also found that the AML1-interacting domain of the Foxp3 protein was located between the FKH domain and the LZ motif (amino acids 278336). Three amino acids located immediately N-terminal to the FKH domain are important for this inhibition, and their mutation (D329V, Y330H, and K332L) impaired Treg suppressive function. Thus, the interaction between AML1 and FOXP3 may be another potential therapeutic target for controlling Treg activity.

\section{FKH DOMAIN}

As a member of Fox family, FOXP3 contains a FKH domain responsible for DNA binding and consequently for its activator/repressor functions. More than half of patients with IPEX syndrome have missense mutations in exons encoding the $\mathrm{FKH}$ domain (70-74). Mutations in the FKH domain of patients with IPEX have been shown to affect DNA binding $(8,51,75)$. FOXP3binding to DNA requires multimerization and it has been shown that FKH domain of FOXP3 forms a domain-swapped dimer, simultaneously engaging and bringing into close proximity two distant FOXP3-binding sites in DNA (55). Thus, it seems that both the DNA-binding FKH domain and an intact LZ domain of FOXP3 are needed for homo-multimerization of FOXP3, DNA binding, and consequently for FOXP3-mediated suppressor functions $(55,76)$.

FOXP3 can regulate gene expression of number of genes that are also targets for NFAT transcription factor. This activity was justified by the capacity of FOXP3 to interact physically with NFAT (60). The mechanism by which FOXP3 influences the expression of NFAT-dependent genes is under study. It has been suggested at least three modes of action of FOXP3 to inhibit the expression of genes regulated by NFAT: (i) by competing with NFAT for binding to DNA (77-79), (ii) by sequestering NFAT away from DNA (based on the finding that NFAT and FOXP3 physically interact in cell lysates (60)) or by sequestering other NFAT partners, such as AP-1 (52), and (iii) by forming a cooperative complex (46) (Figure 1). Regarding the third option, Wu and colleagues showed that the repressive effect of FOXP3 on cytokine gene expression and its activating effect on other genes, such as CTLA4 and CD25, is in fact driven by a cooperative complex formation between NFAT and FOXP3. NFAT binds cooperatively with transcription factors of the AP-1 (Fos/Jun) family to composite NFAT:AP-1 sites, found in the regulatory regions of many genes that are induced during lymphocyte activation (80). But, depending on its partner, NFAT seems to direct two entirely contrary biological programs: (i) $\mathrm{T}$ cell activation by recruiting AP-1 to the regulatory regions of appropriate target genes and (ii) $\mathrm{T}$ cell tolerance by recruiting FOXP3 (46). The cooperative complex FOXP3:NFAT is required to repress expression of the cytokine IL2, upregulate expression of the Treg markers CTLA4 and CD25, and confer suppressor function (46). In a recent paper, Bandukwala et al. (55), solved the crystal structure of the FKH domain of FOXP3 bound to DNA in conjunction with the DNA-binding domain of its partner, NFAT1. This work showed that a region of FOXP3 identified as Wing1, and specially aminoacids 399-401 from FOXP3, inserts into the CX-E'F-fg groove of NFAT that contains a string of positively charged residues, K664, R665, K666, and R667 (55). Mutations that disrupt Foxp3 interaction with NFAT, interfere with the ability of FOXP3 to repress expression of the 

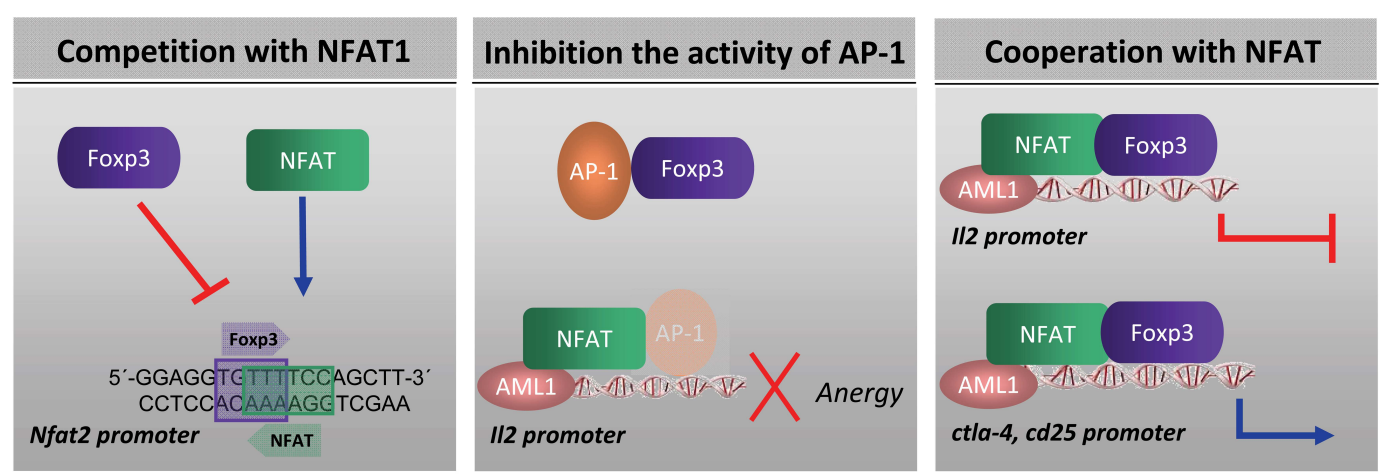

FIGURE 1 | Mechanism by which FOXP3 influences the expression of NFAT-dependent genes: (i) by competing with NFAT for binding to DNA (77-79) (ii) by sequestering NFAT away from DNA (60) or by sequestering other NFAT partners, such as AP-1 (52) and (iii) by forming a FOXP3:NFAT cooperative complex (46).

cytokine IL-2, upregulate expression of the Treg markers CTLA4 and CD25, and the suppressor function (46).

The FKH domain is also implicated in the nuclear localization of FOXP3. Indeed, it has been demonstrated that a C-terminal fragment of Foxp3 containing the entire FKH domain with short flanking sequences at each end was necessary and sufficient for import of FOXP3 to the nucleus (51). However, nuclear import of transcription factors are regulated at multiple levels, including post-translational modifications, binding and release from compartment-specific anchors, and the selective utilization of specific transport factors (81). It is not known whether FOXP3 nuclear translocation can be regulated by other transcription factors. Indeed, it has been shown that the interaction between Foxp3 and c-Rel may contribute to the nuclear translocation of FOXP3 $(60,61)$.

Forkhead domain of FOXP3 has been also implicated in the interaction with the hypoxia-inducible factor 1 (HIF-1 $\alpha$ ). It has been described that HIF-1 enhances Th17 development through direct transcriptional activation of $\operatorname{ROR} \gamma \tau$ and via tertiary complex formation with ROR $\gamma \tau$ and $\mathrm{p} 300$ recruitment to the IL17 promoter. HIF- $1 \alpha$ attenuates $\mathrm{T}$ (reg) development by binding FOXP3 and targeting it for proteasomal degradation (42). These findings highlight the importance of metabolic cues in $\mathrm{T}$ cell fate determination and suggest that metabolic modulation could ameliorate certain $\mathrm{T}$ cell-based immune pathologies.

\section{FOXP3 POST-TRANSLATIONAL MODIFICATIONS}

Post-translational modifications, including phosphorylation, acetylation, ubiquitination, sumoylation, methylation, and hydroxylation, are recognized as important determinants for the dynamic regulation of transcription factors (82). As mentioned above, FOXP3 activity can be regulated by acetylation, a process catalyzed by distinct types of HATs and non-histone proteins that are activated/inhibited in response to extrinsic cellular signals. It has been demonstrated that acetylation/deacetylation of FOXP3, in response to stimuli such as TGF- $\beta$ or IL-6, affects FOXP3 stability and its promoter binding activity $(83,84)$. It is clear that HAT and HDACs, such as TIP60, p300, HDAC7, HDAC9, or SIRT1, are components of the Foxp3 interactome and are involved in regulating the acetylation status of Foxp3 [reviewed in (85)]. FOXP3 acetylation can increase its stability. Indeed, the histone acetyl transferase p300 competes for lysine residues with E3 ubiquitin ligase, which can target FOXP3 for its degradation (86). As mentioned above, FOXP3 degradation directed by HIF-1 $\alpha$ during Th17 development (42).

FOXP3 activity can also be regulated by phosphorylation. The primary structure of FOXP3 contain four cyclin-dependent kinase (CDK) motifs (Ser/Thr-Pro) located within the N-terminal domain. It has been shown very recently that cyclin-dependent kinase 2 (CDK2) together with cyclin E can phophorylate these sites and regulate Foxp3 stability and affect negatively its suppressor function (87). It has also been demonstrated that phosphorylation of FOXP3 at serine 418 affects its transcriptional activity and Treg function (88). The authors showed in rheumatoid arthritisderived Treg cells that Ser 418 was specifically dephosphorylated by protein phosphatase 1 (PP1), whose expression and enzymatic activity ca be induced by tumor necrosis factor $\alpha$ (TNF- $\alpha$ ) leading to impaired Treg-cell function. These data highlight how Treg-cell function may be subverted by pro-inflammatory cytokines such as TNF- $\alpha$ in inflammatory diseases, and how it can be reversed by TNF- $\alpha$ antagonism (88).

\section{FOXP3 AS A TARGET FOR DRUG DEVELOPMENT}

FOXP3 is a multifaceted transcription factor with a major role in the control of immune homeostasis mediated by Treg cells. But also, FOXP3 expression has been shown to be induced transitorily on CD4+ T cells upon TCR stimulation leading to hyporesponsiveness of the cell. This finding suggests that the induction of FOXP3 serves to shut off $\mathrm{T}$ cell activation. It is widely acknowledged that inhibiting Treg-cell function in patients with cancer is essential to improve the efficacy of anti-tumoral therapies. But, on the other hand, FOXP3 has emerged as an important regulator of some oncogenes and as a tumor suppressor factor able to control cell proliferation of tumor cells. Therefore, how should the function of Foxp 3 be inhibited in Treg cells and effector $\mathrm{T}$ cells without altering the beneficial effects of Foxp3 on tumors?

Several strategies have been proposed to neutralize Treg activity. Thus, it has been shown that administration of low doses of 


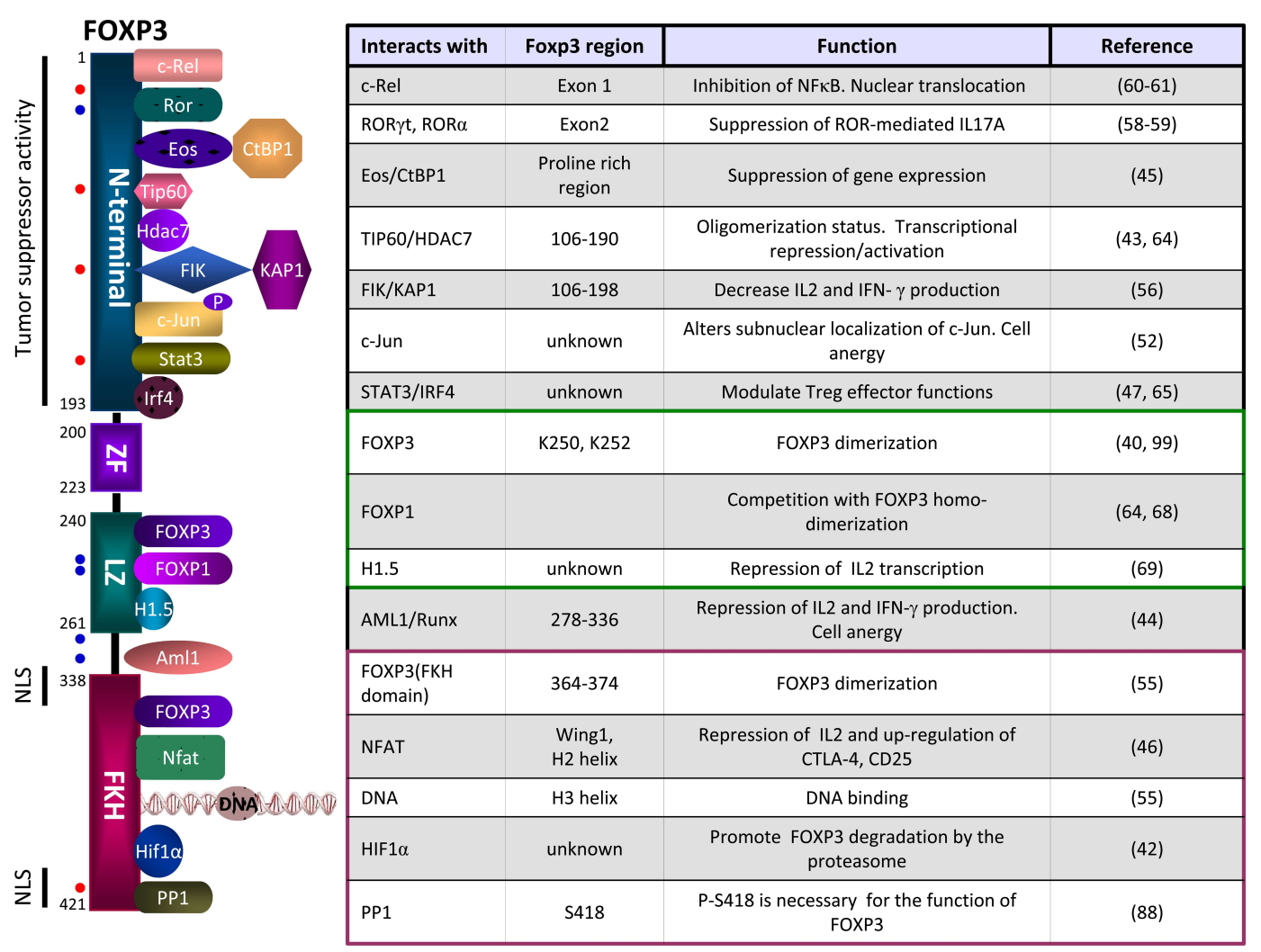

FIGURE 2 | Schematic representation of some of the FOXP3 partners, their site of interactions and functions. The N-terminal domain of FOXP3 can interact with c-Rel (nuclear factor $\kappa B$ transcription factor c-Rel), ROR $\gamma t$ (Retinoic acid receptor-related orphan receptor gamma t), ROR $\alpha$

(Retinoid-related orphan receptor alpha), Eos (Ikaros family zinc finger 4, IKZF4), TIP60 (histone acetyltransferase TIP60), HDAC7 (histone deacetylase 7), FIK (FOXP3-interacting KRAB domain containing protein), c-Jun (transcription factor c-Jun), STAT3 (Signal transducer and activator of transcription 3), IRF4 (interferon regulatory factor 4). The Leucine zipper domain can interact with FOXP3, FOXP1, or H1.5 (Histone H1.5). The FKH domain can interact with FOXP3, NFAT (nuclear factor of activated T cells), the DNA or HIF-1 $\alpha$ (Hypoxia-inducible factor $1 \alpha$ ). Dots in red represent sites of phosphorylation and dots in blue represents sites of acetylation. NLS, nuclear localization sequences. cyclophosphamide is able to deplete Treg and favors anti-tumor therapies (89-91). Also, targeting the alpha-subunit of the IL-2 receptor by using a fusion protein between the IL- 2 and the diphtheria toxin has been tested in clinical trials with different results $(89,90)$. However, these strategies lack of high specificity and might eliminate both effector T cells and Treg cells. In addition, depletion of Treg cells by these strategies also raises the possibility of autoimmunity (91). Other approaches have been directed to inhibit factors produced by Tregs, such us transforming growth factor- $\beta$ (TGF- $\beta$ ). We have shown that a peptide inhibitor of TGF- $\beta$ inhibited Treg activity and improved protective anti-tumor immunogenicity elicited by a vaccine $(92,93)$. These data suggest that inhibition of TGF- $\beta$, in particular by small molecules that might penetrate the interface between contacting $\mathrm{T}$ cells, would be a valuable tool to inhibit Treg activity and consequently, these molecules might be useful to potentiate antiviral or anti-tumor immunotherapies. However, there are other options to regulate Treg activity by targeting FOXP3 directly. As it has been described above, FOXP3 orchestrate a transcriptional network in collaboration with a large number of cofactors, and thus, the complexity of FOXP3 interactome may determine the final outcome of the cell. In Figure 2 we summarize some of the cofactors identified as partners of FOXP3 and through which FOXP3 exerts some of its functions. Regulation of the members of the FOXP3 interactome may offer opportunities for the development of new treatments for autoimmune diseases, cancer, or infectious diseases. In a previous work, using a phage displayed peptide library we identified a 15-mer synthetic peptide, P60, able to enter into the cells, bind to FOXP3, inhibit FOXP3 nuclear translocation, and reduce its ability to suppress the transcription factors NF- $\kappa \mathrm{B}$ and NFAT impairing Treg activity in vitro and in vivo (94). The specific region of FOXP3 which interacts with the peptide has not been elucidated yet, but it is clear that peptide P60 inhibits only certain number of functions ascribed to FOXP3, without altering others.

There are many opportunities to disrupt specific elements of FOXP3 interactome which should be investigated. Thus, small molecules targeting HAT/HDAC or disrupting their interactions with FOXP3 are interesting candidates for the regulation of Treg function in vaccines and tumor therapies (85). Similarly, inhibition of FOXP3 interaction with phospsphorylated c-Jun, Eos, c-Rel, FIK, ROR, AML1, or NFAT might lead to the inhibition of specific functions of FOXP3. Clearly, small molecules targeting 
these proteins are candidates for the regulation of Treg function in vaccines and tumor therapies.

Moreover, there are also opportunities to modulate the posttranslational modifications of FOXP3 by regulating the activity of HAT/HDAC complex (95). Thus, several HDAC inhibitors have been proved to enhance the production and suppressive functions of FOXP3 $(+)$ regulatory $\mathrm{T}$ cells, being effective in murine models of arthritis, allograft rejection, and colitis (9698). Similarly, modification of the phosphorylation status of FOXP3 may offer opportunities to modulate its activity. Strategies to enhance CDK2 and cyclin E activity might downregulate the stability and activity of FOXP3 and control Treg function (87). However, it must be emphasized that new drugs to inhibit FOXP3 functions should preserve its antiproliferative activities which are beneficial for the control of tumor cell growth.

\section{ACKNOWLEDGMENTS}

The work is supported by a grant from Ministerio de Educación y Ciencia (SAF2010-15060 to Juan José Lasarte), and by "UTE project CIMA." Teresa Lozano is a recipient of a FPU grant (Ministerio de Educación, Cultura y Deporte, Spain). Our apologies to those whose related publications were not cited in this review due to space limitations.

\section{REFERENCES}

1. Kaufmann E, Knochel W. Five years on the wings of fork head. Mech Dev (1996) 57:3-20. doi:10.1016/0925-4773(96)00539-4

2. Clark KL, Halay ED, Lai E, Burley SK. Co-crystal structure of the HNF-3/fork head DNA-recognition motif resembles histone H5. Nature (1993) 364:412-20. doi:10.1038/364412a0

3. Kaestner KH, Knochel W, Martinez DE. Unified nomenclature for the winged helix/forkhead transcription factors. Genes Dev (2000) 14:142-6. doi:10.1101/ gad.14.2.142

4. Lehmann OJ, Sowden JC, Carlsson P, Jordan T, Bhattacharya SS. Fox's in development and disease. Trends Genet (2003) 19:339-44. doi:10.1016/S0168-9525(03) 00111-2

5. Brunkow ME, Jeffery EW, Hjerrild KA, Paeper B, Clark LB, Yasayko SA, et al. Disruption of a new forkhead/winged-helix protein, scurfin, results in the fatal lymphoproliferative disorder of the scurfy mouse. Nat Genet (2001) 27:68-73. doi:10.1038/83784

6. Bennett CL, Christie J, Ramsdell F, Brunkow ME, Ferguson PJ, Whitesell L, et al. The immune dysregulation, polyendocrinopathy, enteropathy, X-linked syndrome (IPEX) is caused by mutations of FOXP3. Nat Genet (2001) 27:20-1. doi:10.1038/83713

7. Chatila TA, Blaeser F, Ho N, Lederman HM, Voulgaropoulos C, Helms $\mathrm{C}$, et al. JM2, encoding a fork head-related protein, is mutated in $\mathrm{X}$ linked autoimmunity-allergic disregulation syndrome. J Clin Invest (2000) 106:R75-81. doi:10.1172/JCI11679

8. Wildin RS, Ramsdell F, Peake J, Faravelli F, Casanova JL, Buist N, et al. $\mathrm{X}$-linked neonatal diabetes mellitus, enteropathy and endocrinopathy syndrome is the human equivalent of mouse scurfy. Nat Genet (2001) 27:18-20. doi: $10.1038 / 83707$

9. Blair PJ, Bultman SJ, Haas JC, Rouse BT, Wilkinson JE, Godfrey VL. CD4+CD8$\mathrm{T}$ cells are the effector cells in disease pathogenesis in the scurfy (sf) mouse. J Immunol (1994) 153:3764-74.

10. Sakaguchi S, Sakaguchi N, Asano M, Itoh M, Toda M. Immunologic selftolerance maintained by activated T cells expressing IL-2 receptor alpha-chains (CD25). Breakdown of a single mechanism of self-tolerance causes various autoimmune diseases. J Immunol (1995) 155:1151-64.

11. Suri-Payer E, Amar AZ, Thornton AM, Shevach EM. CD4+CD25+ T cells inhibit both the induction and effector function of autoreactive $\mathrm{T}$ cells and represent a unique lineage of immunoregulatory cells. J Immunol (1998) 160:1212-8.
12. Hori S, Nomura T, Sakaguchi S. Control of regulatory T cell development by the transcription factor Foxp3. Science (2003) 299:1057-61. doi:10.1126/science. 1079490

13. Khattri R, Cox T, Yasayko SA, Ramsdell F. An essential role for Scurfin in CD4+CD25+ T regulatory cells. Nat Immunol (2003) 4:337-42. doi:10.1038/ ni909

14. Aandahl EM, Michaelsson J, Moretto WJ, Hecht FM, Nixon DF. Human $\mathrm{CD} 4+\mathrm{CD} 25+$ regulatory $\mathrm{T}$ cells control T-cell responses to human immunodeficiency virus and cytomegalovirus antigens. J Virol (2004) 78:2454-9. doi:10.1128/JVI.78.5.2454-2459.2004

15. Cabrera R, Tu Z, Xu Y, Firpi RJ, Rosen HR, Liu C, et al. An immunomodulatory role for $\mathrm{CD} 4(+) \mathrm{CD} 25(+)$ regulatory $\mathrm{T}$ lymphocytes in hepatitis $\mathrm{C}$ virus infection. Hepatology (2004) 40:1062-71. doi:10.1002/hep.20454

16. Curiel TJ, Coukos G, Zou L, Alvarez X, Cheng P, Mottram P, et al. Specific recruitment of regulatory $\mathrm{T}$ cells in ovarian carcinoma fosters immune privilege and predicts reduced survival. Nat Med (2004) 10:942-9. doi:10.1038/nm1093

17. Liyanage UK, Moore TT, Joo HG, Tanaka Y, Herrmann V, Doherty G, et al. Prevalence of regulatory $\mathrm{T}$ cells is increased in peripheral blood and tumor microenvironment of patients with pancreas or breast adenocarcinoma. J Immunol (2002) 169:2756-61.

18. Ormandy LA, Hillemann T, Wedemeyer H, Manns MP, Greten TF, Korangy F. Increased populations of regulatory $\mathrm{T}$ cells in peripheral blood of patients with hepatocellular carcinoma. Cancer Res (2005) 65:2457-64. doi:10.1158/00085472.CAN-04-3232

19. Viguier M, Lemaitre F, Verola O, Cho MS, Gorochov G, Dubertret L, et al. Foxp3 expressing $\mathrm{CD} 4+\mathrm{CD} 25$ (high) regulatory $\mathrm{T}$ cells are overrepresented in human metastatic melanoma lymph nodes and inhibit the function of infiltrating $\mathrm{T}$ cells. J Immunol (2004) 173:1444-53.

20. Woo EY, Chu CS, Goletz TJ, Schlienger K, Yeh H, Coukos G, et al. Regulatory $\mathrm{CD} 4(+) \mathrm{CD} 25(+) \mathrm{T}$ cells in tumors from patients with early-stage nonsmall cell lung cancer and late-stage ovarian cancer. Cancer Res (2001) 61: 4766-72.

21. Alvaro T, Lejeune M, Salvado MT, Bosch R, Garcia JF, Jaen J, et al. Outcome in Hodgkin's lymphoma can be predicted from the presence of accompanying cytotoxic and regulatory T cells. Clin Cancer Res (2005) 11:1467-73. doi:10.1158/1078-0432.CCR-04-1869

22. Badoual C, Hans S, Rodriguez J, Peyrard S, Klein C, Agueznay Nel H, et al. Prognostic value of tumor-infiltrating CD4+ T-cell subpopulations in head and neck cancers. Clin Cancer Res (2006) 12:465-72. doi:10.1158/1078-0432.CCR05- 1886

23. Carreras J, Lopez-Guillermo A, Fox BC, Colomo L, Martinez A, Roncador G, et al. High numbers of tumor-infiltrating FOXP3-positive regulatory $\mathrm{T}$ cells are associated with improved overall survival in follicular lymphoma. Blood (2006) 108:2957-64. doi:10.1182/blood-2006-04-018218

24. Ebert LM, Tan BS, Browning J, Svobodova S, Russell SE, Kirkpatrick N, et al. The regulatory $\mathrm{T}$ cell-associated transcription factor FoxP3 is expressed by tumor cells. Cancer Res (2008) 68:3001-9. doi:10.1158/0008-5472.CAN-07-5664

25. Hinz S, Pagerols-Raluy L, Oberg HH, Ammerpohl O, Grussel S, Sipos B, et al. Foxp3 expression in pancreatic carcinoma cells as a novel mechanism of immune evasion in cancer. Cancer Res (2007) 67:8344-50. doi:10.1158/0008-5472.CAN06-3304

26. Niu J, Jiang C, Li C, Liu L, Li K, Jian Z, et al. Foxp3 expression in melanoma cells as a possible mechanism of resistance to immune destruction. Cancer Immunol Immunother (2011) 60:1109-18. doi:10.1007/s00262-011-1025-3

27. Zuo T, Wang L, Morrison C, Chang X, Zhang H, Li W, et al. FOXP3 is an X-linked breast cancer suppressor gene and an important repressor of the HER-2/ErbB2 oncogene. Cell (2007) 129:1275-86. doi:10.1016/j.cell.2007.04.034

28. Nair S, Aldrich AJ, McDonnell E, Cheng Q, Aggarwal A, Patel P, et al. Immunologic targeting of FOXP3 in inflammatory breast cancer cells. PLoS One (2013) 8:e53150. doi:10.1371/journal.pone.0053150

29. Wang L, Liu R, Li W, Chen C, Katoh H, Chen GY, et al. Somatic single hits inactivate the X-linked tumor suppressor FOXP3 in the prostate. Cancer Cell (2009) 16:336-46. doi:10.1016/j.ccr.2009.08.016

30. Zuo T, Liu R, Zhang H, Chang X, Liu Y, Wang L, et al. FOXP3 is a novel transcriptional repressor for the breast cancer oncogene SKP2. J Clin Invest (2007) 117:3765-73. doi:10.1172/JCI32538

31. Redpath M, Xu B, van Kempen LC, Spatz A. The dual role of the X-linked FoxP3 gene in human cancers. Mol Oncol (2011) 5:156-63. doi:10.1016/j.molonc.2011. 03.001 
32. Karanikas V, Speletas M, Zamanakou M, Kalala F, Loules G, Kerenidi T, et al. Foxp3 expression in human cancer cells. J Transl Med (2008) 6:19. doi:10.1186/1479-5876-6-19

33. Gavin MA, Rasmussen JP, Fontenot JD, Vasta V, Manganiello VC, Beavo JA, et al. Foxp3-dependent programme of regulatory T-cell differentiation. Nature (2007) 445:771-5. doi:10.1038/nature05543

34. Lin W, Haribhai D, Relland LM, Truong N, Carlson MR, Williams CB, et al. Regulatory T cell development in the absence of functional Foxp3. Nat Immunol (2007) 8:359-68. doi:10.1038/ni1445

35. Marson A, Kretschmer K, Frampton GM, Jacobsen ES, Polansky JK, MacIsaac KD, et al. Foxp3 occupancy and regulation of key target genes during T-cell stimulation. Nature (2007) 445:931-5. doi:10.1038/nature05478

36. Zheng Y, Josefowicz SZ, Kas A, Chu TT, Gavin MA, Rudensky AY. Genomewide analysis of Foxp 3 target genes in developing and mature regulatory $\mathrm{T}$ cells. Nature (2007) 445:936-40. doi:10.1038/nature05563

37. Fu W, Ergun A, Lu T, Hill JA, Haxhinasto S, Fassett MS, et al. A multiply redundant genetic switch 'locks in' the transcriptional signature of regulatory T cells. Nat Immunol (2012) 13:972-80. doi:10.1038/ni.2420

38. Hill JA, Feuerer M, Tash K, Haxhinasto S, Perez J, Melamed R, et al. Foxp3 transcription-factor-dependent and -independent regulation of the regulatory $\mathrm{T}$ cell transcriptional signature. Immunity (2007) 27:786-800. doi:10.1016/j. immuni.2007.09.010

39. Samstein RM, Arvey A, Josefowicz SZ, Peng X, Reynolds A, Sandstrom R, et al. Foxp3 exploits a pre-existent enhancer landscape for regulatory $\mathrm{T}$ cell lineage specification. Cell (2012) 151:153-66. doi:10.1016/j.cell.2012.06.053

40. Li B, Samanta A, Song X, Iacono KT, Brennan P, Chatila TA, et al. FOXP3 is a homo-oligomer and a component of a supramolecular regulatory complex disabled in the human XLAAD/IPEX autoimmune disease. Int Immunol (2007) 19:825-35. doi:10.1093/intimm/dxm043

41. Rudra D, deRoos P, Chaudhry A, Niec RE, Arvey A, Samstein RM, et al. Transcription factor Foxp3 and its protein partners form a complex regulatory network. Nat Immunol (2012) 13:1010-9. doi:10.1038/ni.2402

42. Dang EV, Barbi J, Yang HY, Jinasena D, Yu H, Zheng Y, et al. Control of $\mathrm{T}(\mathrm{H}) 17 / \mathrm{T}$ (reg) balance by hypoxia-inducible factor 1. Cell (2011) 146:772-84. doi:10.1016/j.cell.2011.07.033

43. Li B, Samanta A, Song X, Iacono KT, Bembas K, Tao R, et al. FOXP3 interactions with histone acetyltransferase and class II histone deacetylases are required for repression. Proc Natl Acad Sci U S A (2007) 104:4571-6. doi:10.1073/pnas. 0700298104

44. Ono M, Yaguchi H, Ohkura N, Kitabayashi I, Nagamura Y, Nomura T, et al. Foxp3 controls regulatory T-cell function by interacting with AML1/Runx1. Nature (2007) 446:685-9. doi:10.1038/nature05673

45. Pan F, Yu H, Dang EV, Barbi J, Pan X, Grosso JF, et al. Eos mediates Foxp3dependent gene silencing in CD4+ regulatory T cells. Science (2009) 325:1142-6. doi:10.1126/science.1176077

46. Wu Y, Borde M, Heissmeyer V, Feuerer M, Lapan AD, Stroud JC, et al. FOXP3 controls regulatory $\mathrm{T}$ cell function through cooperation with NFAT. Cell (2006) 126:375-87. doi:10.1016/j.cell.2006.05.042

47. Zheng Y, Chaudhry A, Kas A, deRoos P, Kim JM, Chu TT, et al. Regulatory T-cell suppressor program co-opts transcription factor IRF4 to control T(H)2 responses. Nature (2009) 458:351-6. doi:10.1038/nature07674

48. Zhou Z, Song X, Li B, Greene MI. FOXP3 and its partners: structural and biochemical insights into the regulation of FOXP3 activity. Immunol Res (2008) 42:19-28. doi:10.1007/s12026-008-8029-x

49. Hori S. The Foxp3 interactome: a network perspective of T(reg) cells. Nat Immunol (2012) 13:943-5. doi:10.1038/ni.2424

50. Gambineri E, Torgerson TR, Ochs HD. Immune dysregulation, polyendocrinopathy, enteropathy, and X-linked inheritance (IPEX), a syndrome of systemic autoimmunity caused by mutations of FOXP3, a critical regulator of Tcell homeostasis. Curr Opin Rheumatol (2003) 15:430-5. doi:10.1097/00002281200307000-00010

51. Lopes JE, Torgerson TR, Schubert LA, Anover SD, Ocheltree EL, Ochs HD, et al. Analysis of FOXP3 reveals multiple domains required for its function as a transcriptional repressor. J Immunol (2006) 177:3133-42.

52. Lee SM, Gao B, Fang D. FoxP3 maintains Treg unresponsiveness by selectively inhibiting the promoter DNA-binding activity of AP-1. Blood (2008) 111:3599-606. doi:10.1182/blood-2007-09-115014
53. Angel P, Karin M. The role of Jun, Fos and the AP-1 complex in cell-proliferation and transformation. Biochim Biophys Acta (1991) 1072:129-57.

54. Heinze E, Chan G, Mory R, Khavari R, Alavi A, Chung SY, et al. Tumor suppressor and T-regulatory functions of Foxp3 are mediated through separate signaling pathways. Oncol Lett (2011) 2:665-8. doi:10.3892/ol.2011.307

55. Bandukwala HS, Wu Y, Feuerer M, Chen Y, Barboza B, Ghosh S, et al. Structure of a domain-swapped FOXP3 dimer on DNA and its function in regulatory T cells. Immunity (2011) 34:479-91. doi:10.1016/j.immuni.2011.02.017

56. Huang C, Martin S, Pfleger C, Du J, Buckner JH, Bluestone JA, et al. Cutting edge: a novel, human-specific interacting protein couples FOXP3 to a chromatin-remodeling complex that contains KAP1/TRIM28. J Immunol (2013) 190:4470-3. doi:10.4049/jimmunol.1203561

57. Allan SE, Passerini L, Bacchetta R, Crellin N, Dai M, Orban PC, et al. The role of 2 FOXP3 isoforms in the generation of human CD4+ Tregs. J Clin Invest (2005) 115:3276-84. doi:10.1172/JCI24685

58. Ichiyama K, Yoshida H, Wakabayashi Y, Chinen T, Saeki K, Nakaya M, et al. Foxp3 inhibits RORgammat-mediated IL-17A mRNA transcription through direct interaction with RORgammat. J Biol Chem (2008) 283:17003-8. doi:10. 1074/jbc.M801286200

59. Zhou L, Lopes JE, Chong MM, Ivanov II, Min R, Victora GD, et al. TGF-betainduced Foxp 3 inhibits $\mathrm{T}(\mathrm{H}) 17$ cell differentiation by antagonizing RORgammat function. Nature (2008) 453:236-40. doi:10.1038/nature06878

60. Bettelli E, Dastrange M, Oukka M. Foxp3 interacts with nuclear factor of activated $\mathrm{T}$ cells and NF-kappa $\mathrm{B}$ to repress cytokine gene expression and effector functions of T helper cells. Proc Natl Acad Sci U S A (2005) 102:5138-43. doi:10.1073/pnas.0501675102

61. Loizou L, Andersen KG, Betz AG. Foxp3 interacts with c-Rel to mediate NF-kappaB repression. PLoS One (2011) 6:e18670. doi:10.1371/journal.pone. 0018670

62. Fraser JD, Irving BA, Crabtree GR, Weiss A. Regulation of interleukin-2 gene enhancer activity by the T cell accessory molecule CD28. Science (1991) 251:313-6. doi:10.1126/science.1846244

63. Liou HC, Hsia CY. Distinctions between c-Rel and other NF-kappaB proteins in immunity and disease. Bioessays (2003) 25:767-80. doi:10.1002/bies. 10306

64. Song X, Li B, Xiao Y, Chen C, Wang Q, Liu Y, et al. Structural and biological features of FOXP3 dimerization relevant to regulatory T cell function. Cell Rep (2012) 1:665-75. doi:10.1016/j.celrep.2012.04.012

65. Chaudhry A, Rudra D, Treuting P, Samstein RM, Liang Y, Kas A, et al. CD4+ regulatory T cells control TH17 responses in a Stat3-dependent manner. Science (2009) 326:986-91. doi:10.1126/science.1172702

66. Darce J, Rudra D, Li L, Nishio J, Cipolletta D, Rudensky AY, et al. An N-terminal mutation of the Foxp3 transcription factor alleviates arthritis but exacerbates diabetes. Immunity (2012) 36:731-41. doi:10.1016/j.immuni.2012.04.007

67. Chae WJ, Henegariu O, Lee SK, Bothwell AL. The mutant leucine-zipper domain impairs both dimerization and suppressive function of Foxp3 in T cells. Proc Natl Acad Sci U S A (2006) 103:9631-6. doi:10.1073/pnas.0600225103

68. Wang B, Lin D, Li C, Tucker P. Multiple domains define the expression and regulatory properties of Foxp1 forkhead transcriptional repressors. J Biol Chem (2003) 278:24259-68. doi:10.1074/jbc.M207174200

69. Mackey-Cushman SL, Gao J, Holmes DA, Nunoya JI, Wang R, Unutmaz D, et al. FoxP3 interacts with linker histone H1.5 to modulate gene expression and program Treg cell activity. Genes Immun (2011) 12:559-67. doi:10.1038/gene. 2011.31

70. Bennett CL, Brunkow ME, Ramsdell F, O’Briant KC, Zhu Q, Fuleihan $\mathrm{RL}$, et al. A rare polyadenylation signal mutation of the FOXP3 gene (AAUAAA $\rightarrow$ AAUGAA) leads to the IPEX syndrome. Immunogenetics (2001) 53:435-9. doi:10.1007/s002510100358

71. Harbuz R, Lespinasse J, Boulet S, Francannet C, Creveaux I, Benkhelifa M, et al. Identification of new FOXP3 mutations and prenatal diagnosis of IPEX syndrome. Prenat Diagn (2010) 30:1072-8. doi:10.1002/pd.2613

72. Owen CJ, Jennings CE, Imrie H, Lachaux A, Bridges NA, Cheetham TD, et al. Mutational analysis of the FOXP3 gene and evidence for genetic heterogeneity in the immunodysregulation, polyendocrinopathy, enteropathy syndrome. J Clin Endocrinol Metab (2003) 88:6034-9. doi:10.1210/jc.2003-031080

73. Rubio-Cabezas O, Minton JA, Caswell R, Shield JP, Deiss D, Sumnik Z, et al. Clinical heterogeneity in patients with FOXP3 mutations presenting with permanent neonatal diabetes. Diabetes Care (2009) 32:111-6. doi:10.2337/dc08-1188 
74. Torgerson TR, Linane A, Moes N, Anover S, Mateo V, Rieux-Laucat F, et al. Severe food allergy as a variant of IPEX syndrome caused by a deletion in a noncoding region of the FOXP3 gene. Gastroenterology (2007) 132:1705-17. doi:10.1053/j.gastro.2007.02.044

75. Bacchetta R, Passerini L, Gambineri E, Dai M, Allan SE, Perroni L, et al. Defective regulatory and effector $\mathrm{T}$ cell functions in patients with FOXP3 mutations. J Clin Invest (2006) 116:1713-22. doi:10.1172/JCI25112

76. Koh KP, Sundrud MS, Rao A. Domain requirements and sequence specificity of DNA binding for the forkhead transcription factor FOXP3. PLoS One (2009) 4:e8109. doi:10.1371/journal.pone.0008109

77. Coffer PJ, Burgering BM. Forkhead-box transcription factors and their role in the immune system. Nat Rev Immunol (2004) 4:889-99. doi:10.1038/nri1488

78. Schubert LA, Jeffery E, Zhang Y, Ramsdell F, Ziegler SF. Scurfin (FOXP3) acts as a repressor of transcription and regulates T cell activation. J Biol Chem (2001) 276:37672-9. doi:10.1074/jbc.M104521200

79. Torgerson TR, Genin A, Chen C, Zhang M, Zhou B, Anover-Sombke S, et al. FOXP3 inhibits activation-induced NFAT2 expression in T cells thereby limiting effector cytokine expression. J Immunol (2009) 183:907-15. doi:10.4049/ jimmunol.0800216

80. Rao A, Luo C, Hogan PG. Transcription factors of the NFAT family: regulation and function. Annu Rev Immunol (1997) 15:707-47. doi:10.1146/annurev. immunol.15.1.707

81. Lee SH, Hannink M. Molecular mechanisms that regulate transcription factor localization suggest new targets for drug development. Adv Drug Deliv Rev (2003) 55:717-31. doi:10.1016/S0169-409X(03)00052-8

82. Huang B, Yang XD, Lamb A, Chen LF. Posttranslational modifications of NFkappaB: another layer of regulation for NF-kappaB signaling pathway. Cell Signal (2010) 22:1282-90. doi:10.1016/j.cellsig.2010.03.017

83. Samanta A, Li B, Song X, Bembas K, Zhang G, Katsumata M, et al. TGF-beta and IL-6 signals modulate chromatin binding and promoter occupancy by acetylated FOXP3. Proc Natl Acad Sci U S A (2008) 105:14023-7. doi:10.1073/pnas. 0806726105

84. van Loosdregt J, Vercoulen Y, Guichelaar T, Gent YY, Beekman JM, van Beekum O, et al. Regulation of Treg functionality by acetylation-mediated Foxp3 protein stabilization. Blood (2010) 115:965-74. doi:10.1182/blood-2009-02207118

85. Xiao Y, Li B, Zhou Z, Hancock WW, Zhang H, Greene MI. Histone acetyltransferase mediated regulation of FOXP3 acetylation and Treg function. Curr Opin Immunol (2010) 22:583-91. doi:10.1016/j.coi.2010.08.013

86. Kwon HS, Lim HW, Wu J, Schnolzer M, Verdin E, Ott M. Three novel acetylation sites in the Foxp3 transcription factor regulate the suppressive activity of regulatory T cells. J Immunol (2012) 188:2712-21. doi:10.4049/jimmunol. 1100903

87. Morawski PA, Mehra P, Chen C, Bhatti T, Wells AD. Foxp3 Protein Stability Is Regulated by Cyclin-dependent Kinase 2. J Biol Chem (2013) 288:24494-502. doi:10.1074/jbc.M113.467704

88. Nie H, Zheng Y, Li R, Guo TB, He D, Fang L, et al. Phosphorylation of FOXP3 controls regulatory $\mathrm{T}$ cell function and is inhibited by TNF-alpha in rheumatoid arthritis. Nat Med (2013) 19:322-8. doi:10.1038/nm.3085
89. Attia P, Maker AV, Haworth LR, Rogers-Freezer L, Rosenberg SA. Inability of a fusion protein of IL-2 and diphtheria toxin (Denileukin Diftitox, DAB389IL-2, ONTAK) to eliminate regulatory $\mathrm{T}$ lymphocytes in patients with melanoma. J Immunother (2005) 28:582-92. doi:10.1097/01.cji.0000175468.19742.10

90. Dannull J, Su Z, Rizzieri D, Yang BK, Coleman D, Yancey D, et al. Enhancement of vaccine-mediated antitumor immunity in cancer patients after depletion of regulatory T cells. J Clin Invest (2005) 115:3623-33. doi:10.1172/JCI25947

91. Ruddle JB, Harper CA, Honemann D, Seymour JF, Prince HM. A denileukin diftitox (Ontak) associated retinopathy? Br J Ophthalmol (2006) 90:1070-1. doi:10.1136/bjo.2006.091165

92. Gil-Guerrero L, Dotor J, Huibregtse IL, Casares N, Lopez-Vazquez AB, Rudilla $\mathrm{F}$, et al. In vitro and in vivo down-regulation of regulatory $\mathrm{T}$ cell activity with a peptide inhibitor of TGF-beta1. J Immunol (2008) 181:126-35.

93. Llopiz D, Dotor J, Casares N, Bezunartea J, Diaz-Valdes N, Ruiz M, et al. Peptide inhibitors of transforming growth factor-beta enhance the efficacy of antitumor immunotherapy. Int J Cancer (2009) 125:2614-23. doi:10.1002/ijc.24656

94. Casares N, Rudilla F, Arribillaga L, Llopiz D, Riezu-Boj JI, Lozano T, et al. A peptide inhibitor of FOXP3 impairs regulatory $\mathrm{T}$ cell activity and improves vaccine efficacy in mice. J Immunol (2010) 185:5150-9. doi:10.4049/jimmunol.1001114

95. Tao R, de Zoeten EF, Ozkaynak E, Chen C, Wang L, Porrett PM, et al. Deacetylase inhibition promotes the generation and function of regulatory T cells. Nat Med (2007) 13:1299-307. doi:10.1038/nm1652

96. de Zoeten EF, Wang L, Sai H, Dillmann WH, Hancock WW. Inhibition of HDAC9 increases T regulatory cell function and prevents colitis in mice. Gastroenterology (2010) 138:583-94. doi:10.1053/j.gastro.2009.10.037

97. Saouaf SJ, Li B, Zhang G, Shen Y, Furuuchi N, Hancock WW, et al. Deacetylase inhibition increases regulatory $\mathrm{T}$ cell function and decreases incidence and severity of collagen-induced arthritis. Exp Mol Pathol (2009) 87:99-104. doi:10.1016/j.yexmp.2009.06.003

98. Wang L, Tao R, Hancock WW. Using histone deacetylase inhibitors to enhance Foxp3(+) regulatory T-cell function and induce allograft tolerance. Immunol Cell Biol (2009) 87:195-202. doi:10.1038/icb.2008.106

Conflict of Interest Statement: The authors declare that the research was conducted in the absence of any commercial or financial relationships that could be construed as a potential conflict of interest.

Received: 16 October 2013; paper pending published: 17 November 2013; accepted: 18 November 2013; published online: 03 December 2013.

Citation: Lozano T, Casares N and Lasarte JJ (2013) Searching for the Achilles heel of FOXP3. Front. Oncol. 3:294. doi: 10.3389/fonc.2013.00294

This article was submitted to Molecular and Cellular Oncology, a section of the journal Frontiers in Oncology.

Copyright (c) 2013 Lozano, Casares and Lasarte. This is an open-access article distributed under the terms of the Creative Commons Attribution License (CC BY). The use, distribution or reproduction in other forums is permitted, provided the original author(s) or licensor are credited and that the original publication in this journal is cited, in accordance with accepted academic practice. No use, distribution or reproduction is permitted which does not comply with these terms. 